\title{
Redefining the Risk of Surgery for Clinical Stage IIIA (N2) Non-Small Cell Lung Cancer: A Pooled Analysis of the STS GTSD and ESTS Registry
}

Andrew T Arndt ( $\square$ Andrew_T_Arndt@rush.edu )

Rush University Medical Center https://orcid.org/0000-0001-5856-9329

Alessandro Brunelli

St James's University Hospital

Silvia Cicconi

University of Liverpool

Pierre-Emmanuel Falcoz

Nouvel Hopital Civil

Michele Salati

University Hospitals of Ancona

\section{Benjamin Kozower}

Washington University School of Medicine in Saint Louis: Washington University in St Louis School of Medicine

Michael J. Liptay

Rush University Medical Center

Gaetano Rocco

Memorial Sloan Kettering Cancer Center

Justin M. Karush

Rush University Medical Center

Nicole Geissen

Rush University Medical Center

\section{Sanjib Basu}

Rush University Medical Center

Christopher W. Seder

Rush University Medical Center

\section{Original Research}

Keywords: Surgery for Clinical Stage IIIA, Pooled Analysis, Pulmonary resection

Posted Date: February 5th, 2021 
DOl: https://doi.org/10.21203/rs.3.rs-173045/v1

License: (c) (1) This work is licensed under a Creative Commons Attribution 4.0 International License. Read Full License 


\section{Abstract}

\section{Background}

Management of clinical stage IIIA-N2 (cllIA-N2) non-small cell lung cancer (NSCLC) remains controversial. We evaluated treatment strategies and outcomes in cIIIA-N2 NSCLC patients who underwent pulmonary resection in The Society of Thoracic Surgeons General Thoracic Surgery Database (STS GTSD) and the European Society of Thoracic Surgeons (ESTS) Registry.

\section{Methods}

The STS GTSD and ESTS Registry were queried for patients who underwent pulmonary resection for cllIAN2 NSCLC between 2012 and 2016. Demographic variables, treatment strategies, and outcome measures were collected and analyzed. Significance of differences was determined using the $X^{2}$ test for categorical variables and the Wilcoxon rank sum test for continuous variables.

Results

Pulmonary resection was performed in 4279 clllA-N2 NSCLC patients (2928 STS GTSD; 1351 ESTS). Induction therapy was administered to $49 \%$. Lobectomy was performed in $67.1 \%$ and pneumonectomy in $13 \%$. Lobectomy was associated with $19.2 \%$ major morbidity and $1.6 \%$ operative mortality, while pneumonectomy was associated with $34.1 \%$ and $5 \%$, respectively. Induction therapy was associated with a higher rate of major morbidity or mortality than upfront surgery $(23.2 \%$ vs. $19.5 \%, p=0.004)$, driven by pneumonectomy $(40.7 \%$ vs. $30.3 \%, p=0.012)$ rather than lobectomy $(20.3 \%$ vs. $18.8 \%, p=0.31)$.

Conclusions

Pulmonary resection for cIIIA-N2 NSCLC is associated with low rates of operative morbidity and mortality, with lobectomy having lower morbidity and mortality than pneumonectomy. Induction therapy, particularly chemoradiotherapy, is associated with a higher rate of composite morbidity or mortality than upfront surgery in pneumonectomy patients but not lobectomy patients.

\section{Introduction}

Lung cancer is the leading cause of cancer death worldwide. [1] Approximately 1 in 4 patients diagnosed with non-small cell lung cancer (NSCLC) in the United States will present with locally advanced disease, with an overall 5-year survival of $29.7 \%$. [2,3] Significant variation in the treatment of stage IIIA-N2 NSCLC exists, both on a national [4] and international level. [5] Furthermore, there is no standard of care based on best medical evidence, as a number of multicenter, randomized controlled trials have demonstrated the efficacy of different multimodality strategies. [6-9]

The INT-0139, a phase III prospective, randomized controlled trial, demonstrated no difference in overall survival between definitive chemoradiotherapy and induction chemoradiotherapy followed by resection 
for patients with stage IIIA-N2 NSCLC. [6] The lack of survival benefit in the surgical arm was partially driven by a $26 \%$ mortality rate following pneumonectomy. [4] However, a recent report from the Society of Thoracic Surgeons General Thoracic Surgery Database (STS GTSD) that examined management of stage IIIA-N2 NSCLC in North America reported excellent results with surgical resection. [10]

The STS GTSD and the European Society of Thoracic Surgeons (ESTS) Registry Taskforces have worked over the past number of years to standardize definitions and terminology for efficient and accurate database collaborations. [11] Building upon this, the current study analyzed pooled STS GTSD and ESTS Registry data to produce contemporary intercontinental outcome data and allow comparison of stagespecific practice patterns for clinical stage IIIA-N2 NSCLC, with the hypothesis that surgical resection, when performed as part of a multi-modality regimen, is associated with low rates of perioperative morbidity and mortality.

\section{Methods}

This study was granted exemption from full review and was therefore approved by the Rush University Medical Center Institutional Review Board.

\section{Data Sources}

The STS GTSD is the largest thoracic database in North America and includes demographic, operative, perioperative, and short-term outcome data. Similarly, the ESTS Registry is a comprehensive European database that maintains data including demographic information, operative details, and perioperative outcomes for thoracic surgical patients. To abide by international data transfer regulations, only aggregate data were obtained from the ESTS Registry.

\section{Patients}

Patients who underwent pulmonary resection for clinical stage IIIA (T1-3N2M0) NSCLC between 2012 and 2016 were identified from the STS GTSD and the ESTS Registry. Demographic variables, disease characteristics, treatment strategies, and outcome measures were defined by STS GTSD or ESTS Registry guidelines. $[12,13]$ Staging was according to the seventh edition of the American Joint Committee on Cancer NSCLC staging system. [14] Pulmonary resection was defined as either thoracoscopic or open: wedge resection, segmentectomy, lobectomy, bilobectomy, or pneumonectomy. Patients younger than 18 years of age and those who underwent non-elective procedures were excluded from analysis.

\section{Variables}

Demographic variables examined from the STS GTSD and ESTS Registry included: age, gender, height, weight, coronary artery disease, diabetes mellitus, dialysis, congestive heart failure, prior cardiothoracic surgery, chronic obstructive pulmonary disease, cigarette smoking (never, past, or current), Zubrod score, clinical staging modality (computed tomography (CT) scan, positron-emission tomography-computed tomography (PET-CT), or invasive staging (endobronchial ultrasound (EBUS), endoscopic ultrasound 
(EUS), or mediastinoscopy)), pathologic stage, and lung cancer histology. Treatment details collected included type of pulmonary resection performed, laterality, and the administration of preoperative chemotherapy and radiotherapy. Perioperative outcome data collected included date of surgery, date of discharge, major morbidity, and 30-day mortality. Major morbidity was defined as: tracheostomy, reintubation, initial ventilator support $>48$ hours, adult respiratory distress syndrome, bronchopleural fistula, pulmonary embolism, pneumonia, unexpected return to the operating room for bleeding, myocardial infarction, deep vein thrombosis requiring treatment, atrial arrhythmia requiring treatment, renal failure (RIFLE criteria), chylothorax, and recurrent laryngeal nerve paralysis.

\section{Statistical Methods}

Descriptive analyses were performed across the populations with patients stratified by upfront surgery, induction chemotherapy followed by surgery, and induction chemoradiotherapy followed by surgery. The groups were compared using the $X^{2}$ test for categorical variables and the Wilcoxon rank sum test for continuous variables. A $p$-value of $<0.05$ was considered statistically significant. Patients who underwent lobectomy and pneumonectomy were the primary focus of this study and were specifically analyzed. These patients were categorized as having had upfront surgery versus any induction therapy; the "any induction" category was then further classified into chemoradiotherapy and chemotherapy subgroups, excluding those that received induction radiation alone.

\section{Results}

\section{Patients}

Between 2012 and 2016, pulmonary resection was performed on a total of 4279 clinical stage IIIA-N2 NSCLC patients: 2928 in the STS GTSD and 1351 ESTS Registry. STS patients were older (mean 65.2 vs 63.3 years, $p<0.001)$, were less likely to be male $(51.8 \mathrm{vs} 70 \%, p<0.001)$, had a higher body mass index ( 27.5 vs $26.1, p<0.001)$, and were more likely to have coronary artery disease $(18.1$ vs $13.8 \%, p=0.001)$, diabetes mellitus ( 15.8 vs $5.1 \%, p<0.001)$, prior cardiothoracic surgery $(14.2$ vs $5.6 \%, p<0.001)$, and COPD (35 vs $24.7 \%, p<0.001)$. ESTS patients had a higher rate of baseline renal failure $(1.9$ vs $0.4 \%, p<$ 0.001 ) and a lower mean DLCO (69.7 vs $71.7 \%$ predicted, $p=0.002)$. [Table 1] 
Table 1

Patient Baseline Characteristics

\begin{tabular}{|c|c|c|c|c|}
\hline & STS + ESTS & STS & ESTS & $\mathrm{p}$ value \\
\hline Total (n) & 4279 & 2928 & 1351 & \\
\hline Age, years (mean \pm SD) & $64.6 \pm 9.81$ & $65.2 \pm 9.9$ & $63.3 \pm 9.5$ & $<0.001$ \\
\hline Male gender (\%) & $57.5(2462)$ & $51.8(1516)$ & $70(946)$ & $<0.001$ \\
\hline Body mass index $\left(\mathrm{kg} / \mathrm{m}^{2} ;\right.$ mean $\left.\pm \mathrm{SD}\right)$ & $27.1 \pm 5.46$ & $27.5 \pm 5.8$ & $26.1 \pm 4.5$ & $<0.001$ \\
\hline \multicolumn{5}{|l|}{ Comorbidities } \\
\hline CAD & $16.8(717)$ & $18.1(531)$ & $13.8(186)$ & 0.001 \\
\hline Diabetes mellitus & $12.4(532)$ & $15.8(463)$ & $5.1(69)$ & $<0.001$ \\
\hline Renal Failure & $0.9(39)$ & $0.4(13)$ & $1.9(26)$ & $<0.001$ \\
\hline $\mathrm{CHF}$ & $2.3(98)$ & $2.2(64)$ & $2.5(34)$ & 0.506 \\
\hline Prior cardiothoracic surgery & $11.5(493)$ & $14.2(417)$ & $5.6(76)$ & $<0.001$ \\
\hline COPD & $31.8(1360)$ & $35.0(1026)$ & $24.7(334)$ & $<0.001$ \\
\hline FEV1\% predicted (mean \pm SD) & $82.7 \pm 19.1$ & $82.5 \pm 19.6$ & $83.0 \pm 18.1$ & 0.427 \\
\hline DLCO $\%$ predicted (mean \pm SD) & $71.1 \pm 19.7$ & $71.7 \pm 20.5$ & $69.7 \pm 17.7$ & 0.002 \\
\hline \multicolumn{5}{|l|}{ Zubrod (STS) or ECOG (ESTS) score } \\
\hline 0 & $41.8(1789)$ & $37.6(1100)$ & $51.0(689)$ & $<0.001$ \\
\hline 1 & $47.6(2038)$ & $57.3(1679)$ & $26.6(359)$ & $<0.001$ \\
\hline II & $4.3(184)$ & $4.1(119)$ & $4.8(65)$ & 0.273 \\
\hline III & $0.8(36)$ & $0.8(22)$ & $1.0(14)$ & 0.345 \\
\hline IV & $0.2(7)$ & $0.1(4)$ & $0.2(3)$ & 0.521 \\
\hline Unknown & $5.3(225)$ & $0.1(4)$ & $16.4(221)$ & $<0.001$ \\
\hline \multicolumn{5}{|l|}{ Clinical staging modality } \\
\hline CT alone & $7.0(300)$ & $4.2(124)$ & $13.0(176)$ & $<0.001$ \\
\hline PET-CT & $83.9(3591)$ & $89.9(2631)$ & $71.1(960)$ & $<0.001$ \\
\hline \multicolumn{5}{|c|}{$\begin{array}{l}\text { All data presented as \% (n), unless otherwise specified. AJCC, American Joint Committee on Cancer; } \\
\text { STS, Society of Thoracic Surgeons; ESTS, European Society of Thoracic Surgeons; CAD, coronary } \\
\text { artery disease; CHF, congestive heart failure; COPD, chronic obstructive pulmonary disease; CT, } \\
\text { computed tomography; DLCO\%pred, diffusion capacity, \% predicted; FEV1\%pred, forced expiratory } \\
\text { volume in } 1 \text { second, \% predicted; PET, positron emission tomography; EBUS-FNA, endobronchial } \\
\text { ultra sound guided-fine needle aspiration. }\end{array}$} \\
\hline
\end{tabular}




\begin{tabular}{|lllll|}
\hline & STS +ESTS & STS & ESTS & p value \\
\hline Invasive mediastinal staging & $45.3(1937)$ & $57.1(1671)$ & $19.7(266)$ & $<0.001$ \\
Clinical T Stage (AJCC 7th Edition) & $18.1(774)$ & $22.0(643)$ & $9.7(131)$ & $<0.001$ \\
$1 \mathrm{a}$ & $17.5(748)$ & $20.0(586)$ & $12.0(162)$ & $<0.001$ \\
$1 \mathrm{~b}$ & $29.2(1248)$ & $30.5(892)$ & $26.3(356)$ & 0.021 \\
2a & $13.4(575)$ & $14.3(420)$ & $11.5(155)$ & 0.017 \\
2b & $16.6(709)$ & $11.1(324)$ & $28.5(385)$ & $<0.001$ \\
3 & $5.6(225)$ & $2.2(63)$ & $12.0(162)$ & $<0.001$ \\
Unknown & & & & \\
\hline $\begin{array}{l}\text { All data presented as \% (n), unless otherwise specified. AJCC, American Joint Committee on Cancer; } \\
\text { STS, Society of Thoracic Surgeons; ESTS, European Society of Thoracic Surgeons; CAD, coronary } \\
\text { artery disease; CHF, congestive heart failure; COPD, chronic obstructive pulmonary disease; CT, } \\
\text { computed tomography; DLCO\%pred, diffusion capacity, \% predicted; FEV1\%pred, forced expiratory } \\
\text { volume in 1 second, \% predicted; PET, positron emission tomography; EBUS-FNA, endobronchial } \\
\text { ultrasound guided-fine needle aspiration. }\end{array}$ & & & \\
\hline
\end{tabular}

\section{Staging}

Most patients in the combined cohort had a PET-CT (83.9\%) rather than a CT alone (7\%) for radiographic staging. ESTS patients were more likely to be staged by CT alone (13 vs $4.2 \%, p<0.001$ ), whereas STS patients were more likely to have a PET-CT ( 89.9 vs $71.1 \%, p<0.001)$. Overall, $45.3 \%$ of patients underwent invasive mediastinal staging, with STS patients more likely to undergo invasive mediastinal staging than ESTS patients ( 57.1 vs $19.7 \%, p<0.001$ ). STS patients were more likely to present with $\mathrm{T} 1 \mathrm{a}$, T1b, T2a, or T2b than ESTS patients, whereas ESTS patients had a higher rate of clinical T3 lesions (28.5 vs $11.1 \%, p<0.001)$.

\section{Treatment Strategy}

In the combined cohort, $48.9 \%$ of patients underwent induction treatment, with STS patients being more likely to have received induction therapy than ESTS patients ( 52.5 vs $41.2 \%, p<0.001)$. [Table 2] STS patients were more likely to have chemoradiotherapy than chemotherapy alone (32.6 vs $19.9 \%, p<0.001)$, whereas ESTS patients were more likely to have chemotherapy alone $(29.4 \mathrm{vs} 11.8 \%, \mathrm{p}<0.001)$. 
Table 2

Treatment Strategy

\begin{tabular}{|c|c|c|c|c|}
\hline & STS + ESTS & STS & ESTS & $\mathrm{p}$ value \\
\hline Induction Therapy & 48.9 (2093) & $52.5(1537)$ & $41.2(556)$ & $<0.001$ \\
\hline Induction chemotherapy & $22.9(980)$ & $19.9(583)$ & $29.4(397)$ & $<0.001$ \\
\hline Induction chemoradiotherapy & $26.0(1113)$ & $32.6(954)$ & $11.8(159)$ & $<0.001$ \\
\hline Minimally invasive & $31.0(1328)$ & $37.8(1106)$ & $16.4(222)$ & $<0.001$ \\
\hline Thoracotomy & $68.4(2927)$ & $62.1(1818)$ & $82.1(1109)$ & $<0.001$ \\
\hline \multicolumn{5}{|l|}{ Primary procedure } \\
\hline Wedge resection & $7.2(310)$ & $8.3(242)$ & $5.0(68)$ & $<0.001$ \\
\hline Segmentectomy & $2.2(96)$ & $2.3(68)$ & $2.1(28)$ & 0.612 \\
\hline Lobectomy & $67.1(2871)$ & $69.2(2027)$ & $62.5(844)$ & 0.012 \\
\hline Sleeve lobectomy & $3.8(164)$ & $2.7(78)$ & $6.4(86)$ & $<0.001$ \\
\hline Bilobectomy & $6.5(280)$ & $6.2(181)$ & $7.3(99)$ & 0.173 \\
\hline Pneumonectomy & $13.0(558)$ & $11.3(332)$ & $16.7(226)$ & $<0.001$ \\
\hline \multicolumn{5}{|l|}{ Histopathology } \\
\hline Adenocarcinoma & $24.9(1065)$ & $24.8(725)$ & $25.2(340)$ & 0.805 \\
\hline Squamous cell carcinoma & $12.0(512)$ & $11.1(326)$ & $13.8(186)$ & 0.021 \\
\hline Neuroendocrine & $1.9(80)$ & $2.3(66)$ & $1.0(14)$ & 0.007 \\
\hline Mixed histology & $1.0(43)$ & $0.9(27)$ & $1.2(16)$ & 0.427 \\
\hline Unknown & 60.3 (2579) & 60.9 (1784) & $58.8(795)$ & 0.415 \\
\hline \multicolumn{5}{|l|}{ Pathologic stage } \\
\hline $\mathrm{pCR}$ & $5.4(229)$ & $6.6(193)$ & $2.7(36)$ & $<0.001$ \\
\hline IA & $12.6(538)$ & $12.3(360)$ & $13.2(178)$ & 0.450 \\
\hline IB & $6.8(290)$ & $8.2(239)$ & $3.8(51)$ & $<0.001$ \\
\hline$\| \mathrm{A}$ & $8.7(373)$ & $10.1(295)$ & $5.8(78)$ & $<0.001$ \\
\hline IIB & $7.6(324)$ & $7.6(223)$ & $7.5(101)$ & 0.877 \\
\hline IIIA & 42.3 (1835) & $46.3(1357)$ & 35.4 (478) & $<0.001$ \\
\hline
\end{tabular}

All data presented as \% (n). STS, Society of Thoracic Surgeons; ESTS, European Society of Thoracic Surgeons. 


\begin{tabular}{|lllll|}
\hline & STS + ESTS & STS & ESTS & P value \\
\hline IIIB & $2.5(107)$ & $2.2(65)$ & $3.1(42)$ & 0.087 \\
\hline IV & $1.5(65)$ & $1.6(47)$ & $1.3(18)$ & 0.501 \\
TX or NX or Unknown & $12.1(518)$ & $5.1(149)$ & $27.3(369)$ & $<0.001$ \\
\hline $\begin{array}{l}\text { All data presented as \% (n). STS, Society of Thoracic Surgeons; ESTS, European Society of Thoracic } \\
\text { Surgeons. }\end{array}$ & & & \\
\hline
\end{tabular}

Minimally invasive surgical techniques were employed $31 \%$ of the time, with the STS cohort being more likely than the ESTS cohort to have undergone minimally invasive surgery ( 37.8 vs $16.4 \%, p<0.001)$. Among upfront surgery patients, $57.5 \%$ of STS and $18 \%$ of ESTS patients had minimally invasive surgery. The most commonly performed procedure was lobectomy at $67.1 \%$. Pneumonectomy was performed in $13 \%$ of patients overall and was the second most common operation in each database.

\section{Pathology}

While histopathology was unknown in $60.3 \%$ of patients ( 60.9 and $58.8 \%$ in STS and ESTS patients, respectively), the most common reported histopathology was adenocarcinoma, accounting for $24.9 \%$ of overall diagnoses and $65.7 \%$ of patients with a documented histopathology. The most common pathologic stage was IIIA, found in $42.3 \%$ of patients in the combined group. Among upfront surgery patients in the combined group, nodal overstaging (clinical N2, pathologic N0/1) occurred in $47.8 \%$ (998/2088).

\section{Major Morbidity}

The major morbidity rate in the combined cohort was $20.8 \%$, with no difference between the STS and ESTS cohorts ( 21.4 vs $19.4 \%, p=0.185$ ). [Table 3 ] The 30 -day mortality was $2 \%$ overall, with no difference between the STS and ESTS cohorts ( $2.1 \mathrm{vs} 1.9 \%, \mathrm{p}=0.735)$. The STS group had a significantly higher rate of tracheostomy (1.2 vs $0.3 \%, p=0.042$ ), reintubation ( 2.1 vs $1.2 \%, p=0.036$ ), unexpected return to OR for bleeding (4.6 vs $1.3 \%, p<0.001)$, DVT requiring treatment ( 1 vs $0.1 \%, p=0.001)$, and atrial arrhythmia requiring treatment $(12.6 \mathrm{vs} 8.3 \%, \mathrm{p}<0.001)$. The ESTS cohort had a higher rate of pneumonia $(7.8 \mathrm{vs}$ $5.2 \%, p=0.002)$ and a greater length of stay (7.6 vs 6.3 days, $p<0.001)$. 
Table 3

Frequency of complications

\begin{tabular}{|c|c|c|c|c|}
\hline & STS + ESTS & STS & ESTS & $\mathrm{p}$ value \\
\hline Major morbidity & $20.8(888)$ & $21.4(626)$ & $19.4(262)$ & 0.185 \\
\hline Tracheostomy & $0.9(39)$ & $1.2(35)$ & $0.3(4)$ & 0.042 \\
\hline Reintubation & $1.8(78)$ & $2.1(62)$ & $1.2(16)$ & 0.036 \\
\hline Initial ventilatory support $>48$ Hours & $0.7(29)$ & $0.8(22)$ & $0.5(7)$ & 0.389 \\
\hline Adult Respiratory Distress Syndrome & $0.9(39)$ & $1.0(30)$ & $0.7(9)$ & 0.254 \\
\hline Bronchopleural fistula & $0.5(21)$ & $0.5(16)$ & $0.4(5)$ & 0.444 \\
\hline Pulmonary embolus & $0.5(21)$ & $0.6(17)$ & $0.3(4)$ & 0.217 \\
\hline Pneumonia & $6.0(258)$ & $5.2(153)$ & $7.8(105)$ & 0.002 \\
\hline $\begin{array}{l}\text { Unexpected return to operating room (for } \\
\text { bleeding) }\end{array}$ & $3.6(154)$ & $4.6(136)$ & $1.3(18)$ & $<0.001$ \\
\hline Myocardial infarction & $0.3(13)$ & $0.4(12)$ & $0.1(1)$ & 0.064 \\
\hline DVT requiring treatment & $0.7(29)$ & $1.0(28)$ & $0.1(1)$ & 0.001 \\
\hline Atrial arrhythmia requiring treatment & $11.2(480)$ & $12.6(368)$ & $8.3(112)$ & $<0.001$ \\
\hline Renal failure (RIFLE criteria) & $1.2(51)$ & $1.3(37)$ & $1.0(14)$ & 0.527 \\
\hline Chylothorax & $0.8(35)$ & $0.7(21)$ & $1.0(14)$ & 0.283 \\
\hline Recurrent laryngeal nerve paralysis & $1.6(69)$ & $1.7(51)$ & $1.3(18)$ & 0.327 \\
\hline 30-day mortality & $2.0(87)$ & $2.1(61)$ & $1.9(26)$ & 0.735 \\
\hline Hospital length of stay (days, mean \pm SD) & $6.7 \pm 5.8$ & $6.3 \pm 6.6$ & $7.6 \pm 3.3$ & $<0.001$ \\
\hline
\end{tabular}

All data presented as \% (n). STS, Society of Thoracic Surgeons; ESTS, European Society of Thoracic Surgeons; DVT, deep vein thrombosis; SD, standard deviation.

\section{Major Morbidity or Mortality for Lobectomy and Pneumonectomy by Treatment Strategy}

Overall, lobectomy was associated with $19.2 \%$ major morbidity and $1.6 \%$ operative mortality, while pneumonectomy was associated with $34.1 \%$ major morbidity and $5 \%$ operative mortality. [Table 4] Among patients who underwent lobectomy or pneumonectomy, induction therapy was associated with a higher rate of composite major morbidity or mortality than upfront surgery $(23.2$ vs $19.5 \%, p=0.004)$. The increased risk of morbidity or mortality with induction therapy was driven by patients who underwent pneumonectomy (40.7 vs $30.3 \%$ complication rate in induction vs upfront surgery, $p=0.012$ ) rather than 
lobectomy ( 20.3 vs $18.8 \%$ complication rate in induction vs upfront surgery, $p=0.31$ ). Induction chemoradiotherapy was associated with a higher rate of composite morbidity or mortality than induction chemotherapy ( 25.2 vs $20.9 \%, p=0.025)$ in patients who underwent lobectomy or pneumonectomy. Similarly, the increased risk of morbidity or mortality with induction chemoradiotherapy vs induction chemotherapy alone was driven by patients who underwent pneumonectomy $(46.2$ vs $34.6 \%, p=0.05)$ rather than lobectomy $(22.1$ vs $18.2 \% ; p=0.06)$. 
Table 4

Major morbidity and mortality stratified by treatment strategy

\begin{tabular}{|c|c|c|c|c|}
\hline & (n) & $\begin{array}{l}\text { Major } \\
\text { Morbidity }\end{array}$ & Mortality & $\begin{array}{l}\text { Major Morbidity or } \\
\text { Mortality }\end{array}$ \\
\hline $\begin{array}{l}\text { All Lobectomy or } \\
\text { Pneumonectomy* }\end{array}$ & 3428 & $21.6(739)$ & $2.2(74)$ & $22.1(758)$ \\
\hline Lobectomy** & 2886 & $19.2(554)$ & $1.6(47)$ & $19.6(565)$ \\
\hline Pneumonectomy & 542 & $34.1(185)$ & $5.0(27)$ & 35.6 (193) \\
\hline Right Pneumonectomy & 237 & $31.2(74)$ & $5.5(13)$ & $33.8(80)$ \\
\hline Left Pneumonectomy & 275 & $36.7(101)$ & $4.7(13)$ & $37.5(103)$ \\
\hline Upfront Surgery & 1929 & $18.9(365)$ & $1.9(37)$ & $19.5(376)$ \\
\hline Lobectomy & 1372 & $18.4(253)$ & $1.7(23)$ & $18.8(258)$ \\
\hline Pneumonectomy & 267 & $28.5(76)$ & $3.7(10)$ & $30.3(81)$ \\
\hline Right Pneumonectomy & 111 & $27.9(31)$ & $5.4(6)$ & $31.5(35)$ \\
\hline Left Pneumonectomy & 131 & $28.2(37)$ & $2.3(3)$ & $29.0(38)$ \\
\hline Any Induction $\diamond$ Surgery & 1978 & $22.8(451)$ & $2.3(45)$ & $23.2(460)$ \\
\hline Lobectomy & 1514 & $19.9(301)$ & $1.6(24)$ & $20.3(307)$ \\
\hline Pneumonectomy & 275 & $39.6(109)$ & $6.2(17)$ & $40.7(112)$ \\
\hline Right Pneumonectomy & 126 & $33.3(43)$ & $5.6(7)$ & $35.7(45)$ \\
\hline Left Pneumonectomy & 144 & $44.4(64)$ & $6.9(10)$ & $45.1(65)$ \\
\hline Chemoradiotherapy $\diamond$ Surgery & 1075 & $24.8(267)$ & $2.5(27)$ & $25.2(271)$ \\
\hline Lobectomy & 816 & $21.6(176)$ & $1.6(13)$ & $22.1(180)$ \\
\hline Pneumonectomy & 145 & $46.2(67)$ & $6.9(10)$ & $46.2(67)$ \\
\hline Right Pneumonectomy & 63 & $36.5(23)$ & $6.3(4)$ & $36.5(23)$ \\
\hline Left Pneumonectomy & 79 & $53.2(42)$ & $7.6(6)$ & $53.2(42)$ \\
\hline Chemotherapy $\diamond$ Surgery & 903 & $20.4(184)$ & $2.0(18)$ & $20.9(189)$ \\
\hline Lobectomy & 698 & $17.9(125)$ & $1.6(11)$ & $18.2(127)$ \\
\hline Pneumonectomy & 130 & $32.3(42)$ & $5.4(7)$ & $34.6(45)$ \\
\hline \multicolumn{5}{|l|}{ All data presented as $\%(n)$. } \\
\hline \multicolumn{5}{|c|}{ *Data include patients who underwent radiation alone followed by surgery } \\
\hline$\star \star$ Sleeve lobectomy patients in & & & & \\
\hline
\end{tabular}




\begin{tabular}{|lllll}
\hline & $(n)$ & $\begin{array}{l}\text { Major } \\
\text { Morbidity }\end{array}$ & Mortality & $\begin{array}{l}\text { Major Morbidity or } \\
\text { Mortality }\end{array}$ \\
\hline Right Pneumonectomy & 63 & $31.7(20)$ & $4.8(3)$ & $34.9(22)$ \\
\hline Left Pneumonectomy & 65 & $33.8(22)$ & $6.2(4)$ & $35.4(23)$ \\
\hline
\end{tabular}

All data presented as $\%(n)$.

*Data include patients who underwent radiation alone followed by surgery

**Sleeve lobectomy patients included

Examining mortality, patients who underwent any induction therapy had a $1.6 \%$ and $6.2 \%$ mortality rate with lobectomy and pneumonectomy, respectively. Mortality in the post-induction right pneumonectomy group was similar to the post-induction left pneumonectomy group $(5.6 \%$ vs. $6.9 \%, p=0.661)$.

\section{Discussion}

This study pooled 4279 clinical stage IIIA-N2 NSCLC patients from the STS GTSD and ESTS Registry, allowing for a robust analysis of a heterogeneous patient population. The results suggest pulmonary resection, as part of a multi-modality approach, is associated with low rates of perioperative morbidity and mortality, with lobectomy having lower morbidity and mortality than pneumonectomy. In addition, induction therapy, particularly chemoradiotherapy, is associated with a higher rate of composite morbidity or mortality than upfront surgery in pneumonectomy patients but not lobectomy patients.

These data highlight that radiographic and invasive mediastinal staging practices vary widely for clinical stage IIIA-N2 NSCLC. Despite being recommended for all clinical stage IIIA-N2 NSCLC patients by the American College of Chest Physicians [15] and the European Society of Thoracic Surgeons, [16] only $89.9 \%$ of STS and $71.1 \%$ of ESTS patients underwent PET-CT. Similarly, invasive mediastinal staging is recommended for clinical stage IIIA-N2 NSCLC patients $[15,16]$ but was performed only $45.3 \%$ of patients in the combined cohort. Invasive mediastinal staging was more frequently performed in the STS group than in the ESTS group (57.1 vs $19.7 \%$ ). Perhaps the lower rate of invasive mediastinal staging in the ESTS group is explained by the higher rate of clinical T3 presentation ( $28.5 \mathrm{vs} 11.1 \%, \mathrm{p}<0.001)$, and a radiographic T3N2 was more likely to be accepted as accurate and less likely to prompt invasive mediastinal staging than a radiographic T1-2N2 patient. A more likely explanation may be that surgeons and treatment teams in both the STS and ESTS used clinical judgment in determining which patients would benefit from invasive mediastinal staging. Examples could include a surgeon not judging lymph nodes that were "barely" over $1 \mathrm{~cm}$ or nodes that were faintly FDG avid to be high yield for biopsy despite a strict radiographic designation of $\mathrm{N} 2$ and a recommendation for invasive mediastinal staging. $[15,16]$

An equally surprising finding was the low rate of induction therapy use for clinical stage IIIA-N2 NSCLC patients. In the combined STS and ESTS cohort, only $48.9 \%$ of patients underwent induction chemotherapy or chemoradiotherapy (52.5\% in STS; $41.2 \%$ in ESTS). This number is particularly 
noteworthy given that the cohort included only pretreatment, clinically N2 patients and is not reflective of nodal upstaging or "surprise" N2 disease in a group of clinical N0-1 patients; therefore, this group would be advised to undergo induction therapy by most current guidelines. [17] As with the possibility that some surgeons omitted invasive mediastinal staging in patients for whom they felt it was low yield, it is possible that this same subset of patients with mediastinal adenopathy that was deemed "borderline" would have at times undergone upfront surgery rather than induction treatment. However, clinical leeway in such "borderline" situations seems unlikely to account for such a disparity between recommendation and actual practice.

In line with previous literature [5], STS patients who underwent induction therapy were more likely to have chemoradiotherapy than chemotherapy alone, while ESTS patients were more likely to receive chemotherapy alone rather than chemoradiotherapy. As evidence mounts supporting the role of induction chemotherapy over chemoradiotherapy, increasing numbers of patients in both the STS GTSD and the ESTS Registry may receive induction chemotherapy alone in the future. [18]

Surgical management of clinical stage IIIA-N2 NSCLC was predominantly with an open lobectomy. Pneumonectomy was more common in the ESTS Registry than in the STS GTSD. The frequencies of lobectomy and pneumonectomy in the current study are consistent with other recently published reports. [10] Additionally, the rate of nodal overstaging noted in the upfront surgery group was in line with previous reports. [10] The overall mortality for lobectomy in the combined cohort was $1.6 \%$, which did not differ for the upfront surgery, induction chemoradiotherapy, or induction chemotherapy groups. Overall mortality for the pneumonectomy group was $5 \%$ with similar rates between the induction chemotherapy only and chemoradiotherapy patients. This finding is in line with a recent report from the ESTS Database Committee that post-induction pneumonectomy, in a largely chemotherapy only cohort, was not associated with a higher mortality than pneumonectomy without induction therapy. [19] Additionally, in contradiction to some prior reports [20], post-induction right pneumonectomy in this study did not carry a higher rate of mortality than post-induction left pneumonectomy. However, this finding is consistent with other reports that demonstrated no difference in post-induction mortality between right and left pneumonectomy. [10].

This study has certain limitations. The STS GTSD and the ESTS Registry are voluntary databases that do not capture all surgically managed NSCLC patients and likely reflect trends at major academic and tertiary care centers-with care rendered by "expert teams." The STS includes participating hospitals from the United States, Israel, Singapore, and the United Arab Emirates; 32\% are teaching hospitals. [21] The ESTS includes participating hospitals from Albania, Austria, Belgium, Croatia, France, Germany, Greece, Hungary, Italy, the Netherlands, Poland, Portugal, Romania, Slovakia, Slovenia, Spain, Switzerland, Turkey, and the United Kingdom; $19.4 \%$ are teaching hospitals. [22] Therefore, while this study's 5\% operative mortality for pneumonectomy after induction therapy is in line with other recent published reports of STS and ESTS data, $[10,19]$ this outcome may not be generalizable to every hospital. In addition, the inability to compare patient-level data between the STS GTSD and the ESTS Registry limits the conclusions that can be drawn. Without the ability to risk adjust, comparing outcomes become difficult; this report is purely 
descriptive, and caution should be used when interpreting the findings in this unadjusted dataset. Additional limitations include lack of information on number of lymph node stations involved, which would improve granularity of the dataset given the heterogeneous nature of the disease, and high rate of unknown pathology.

In conclusion, this study suggests that pulmonary resection for cIllA-N2 NSCLC is associated with low rates of operative morbidity and mortality, with lobectomy having lower morbidity and mortality rates than pneumonectomy. Induction therapy, particularly chemoradiotherapy, is associated with a higher rate of composite morbidity or mortality than upfront surgery in pneumonectomy patients but not lobectomy patients. In addition, this report highlights that there is room for improvement in both radiographic and invasive staging in patients with clinical stage IIIA-N2 NSCLC.

\section{Declarations}

\section{Acknowledgements}

The data for this research were provided by the Society of Thoracic Surgeons' National Database Participant User File Research Program. Data analysis was performed at the investigators' institutions.

\section{Funding}

This study was funded by the Department of Cardiovascular and Thoracic Surgery, Rush University Medical Center, Chicago, IL, USA.

\section{Disclosures}

The authors have no conflicts of interest.

\section{Presentation}

This abstract has been accepted for oral presentation at The Society of Thoracic Surgeons 2020 Annual Meeting, January 25-28, 2020 in New Orleans, LA, USA.

\section{Synopsis}

Management of clinical stage IIIA-N2 (cIIIA-N2) non-small cell lung cancer (NSCLC) remains controversial. A pooled analysis of the STS GTSD and ESTS Registry found that pulmonary resection for clllA-N2 NSCLC is associated with low rates of operative morbidity and mortality.

\section{References}

[1] Siegel R, Miller KD, Jemal A. Cancer statistics, 2018. CA Cancer J Clin 2018;68(1):7-30. 
[2] Noone AM, Howlader N, Krapcho M, et al. SEER Cancer Statistics Review, 1975-2015, National Cancer Institute. Bethesda, MD, https://seer.cancer.gov/csr/1975_2015/, based on November 2017 SEER data submission, posted to the SEER web site, April 2018.

[3] Goldstraw P, Chansky K, Crowley J, et al. The IASLC Lung Cancer Staging Project: proposals for revision of the TNM stage groupings in the forthcoming (eighth) edition of the TNM classification for lung cancer. J Thorac Onc 2016;11(1):39-51.

[4] Veeramachaneni NK, Fein RH, Stephenson BJK, LJ Edwards, Fernandez FG. Management of stage IIIA non-small cell lung cancer by thoracic surgeons in North America. Ann Thorac Surg 2012;94:922-8

[5] Seder CW, Salati M, Kozower BD, et al. Variation in pulmonary resection practices between the Society of Thoracic Surgeons and the European Society of Thoracic Surgeons General Thoracic Surgery Databases. Ann Thorac Surg 2016;101(6):2077-84.

[6] Albain KS, Swann RS, Rusch VW, et al. Radiotherapy plus chemotherapy with or without surgical resection for stage III non-small-cell lung cancer: a phase III randomised controlled trial. Lancet 2009;374:379-86.

[7] Albain KS, Rusch VW, Crowley JJ, et al. Concurrent cisplatin/etoposide plus chest radiotherapy followed by surgery for stages IIIA (N2) and IIIB non-small-cell lung cancer: mature results of Southwest Oncology Group Phase II Study 8805. J Clin Oncol 1995;13:1880-92.

[8] van Meerbeeck JP, Kramer GW, Van Schil PE, et al. Randomized controlled trial of resection versus radiotherapy after induction chemotherapy in stage IIIA-N2 non-small-cell lung cancer. J Natl Cancer Inst 2007;99(6):442-50.

[9] Thomas M, Rübe C, Hoffknecht P, et al. Effect of preoperative chemoradiation in addition to preoperative chemotherapy: a randomised trial in stage III non-small-cell lung cancer. Lancet Oncol 2008;9(7):636-48.

[10] Boffa D, Fernandez FG, Kim S, et al. Surgically managed clinical stage IIIA-clinical N2 lung cancer in the Society of Thoracic Surgeons Database. Ann Thorac Surg 2017;104:395-403.

[11] Fernandez FG, Falcoz PE, Kozower BD, et al. The Society of Thoracic Surgeons and The European Society of Thoracic Surgeons General Thoracic Surgery Databases: joint standardization of variable definitions and terminology. Ann Thorac Surg 2015;99:368-76.

[12] Society of Thoracic Surgeons General Thoracic Surgery Database Training Manual: Version 2.3. Available at

www.sts.org/sites/default/files/documents/August28_v2.3_GTSD_Training_Manual.pdf (Accessed August 27, 2018) 
[13] European Society of Thoracic Surgery Annual Database Report (2016). Available at http://www.ests.org/_userfiles/pages/files/ESTS\%202016Silver_Book_FULL_FINAL_14.50.pdf (accessed August 27, 2018)

[14] Detterbeck FC, Boffa DJ, Tanoue LT. The new lung cancer staging system. Chest 2009;136:260-271.

[15] Silvestri GA, Gonzalez AV, Jantz MA, et al. Methods for staging non-small cell lung cancer: diagnosis and management of lung cancer, 3rd ed: American College of Chest Physicians Evidence-Based Clinical Practice Guidelines. Chest 2013;143(5 Suppl):e211S-50S.

[16] De Leyn P, Dooms C, Kuzdzal J, et al. Revised ESTS guidelines from preoperative mediastinal lymph node staging for non-small-cell lung cancer. Eur J Cardiothorac Surg 2014;45(5)787-98.

[17] Ramnath N, Dilling TJ, Harris LJ, et al. Treatment of stage III non-small cell lung cancer: diagnosis and management of lung cancer, 3rd ed: American College of Chest Physicians Evidence-Based Clinical Practice Guidelines. Chest 2013;143(5 Suppl):e314S-40S.

[18] Blumenthal GM, Bunn PA, Jr., Chaft JE, et al. Current status and future perspectives on neoadjuvant therapy in lung cancer. J Thorac Oncol 2018;13:1818-31.

[19] Brunelli A, Rocco G, Szanto Z, et al. Morbidity and mortality of lobectomy or pneumonectomy after neoadjuvant treatment; an analysis from the ESTS database. Eur J Cardiothorac Surg 2020:57(4)740-46.

[20] Yang CJ, Shah SA, Lin BK, et al. Right-sided versus left-sided pneumonectomy after induction therapy for non-small cell lung cancer. Ann Thorac Surg 2019;107:1074-81.

[21] Email communication with Adelaide Dolan, Database Coordinator, STS National Database.

[22] Email communication with Stefano Passani, MD MHM. 